doi:10.12662/2359-618xregea.v5i2.p124-134.2016

\title{
ENSAIOS
}

\section{A PROTEÇÃO À PROPRIEDADE INDUSTRIAL DAS MARCAS NA VISÃO DO SUPERIOR TRIBUNAL DE JUSTIÇA}

\section{RESUMO}

Mais comum do que se imagina é a prática, reprovável sob o ponto de vista jurídico, de se criarem marcas e símbolos de bens ou produtos similares àqueles já consagrados e consolidados no mercado, fazendo que o consumidor se confunda por ocasião da escolha do produto. Este cenário foi submetido ao Poder Judiciário, especificamente ao Superior Tribunal de Justiça, em várias ocasiões, mas dois casos chamaram a atenção pela notoriedade das marcas: a Bombril, cujo símbolo é deveras reconhecido na área da limpeza e higiene doméstica, e os salgadinhos Cheetos, bem a gosto da clientela infantil. Assim, empresas e indústrias, ainda que gerem produtos de qualidade, preferem a artimanha de utilizar em suas embalagens símbolos ou emblemas muito próximos daquelas marcas já reconhecidas, na tentativa irregular de atrair consumidores e ferindo os princípios básicos da livre iniciativa e da concorrência leal. Diante da conjuntura, o Poder Judiciário vem consolidando jurisprudência no intuito de efetivamente proteger marcas, símbolos e emblemas já consagrados no gosto público. As mais recentes decisões judiciais acerca do assunto constituem, justamente, o tema básico do presente ensaio, o qual será construído a partir da análise jurisprudencial pertinente, bem como, subsidiariamente, dos estudos doutrinários e das regras normativas inerentes ao assunto. Aliás, parecem não merecer qualquer conserto tais decisões, pois são coadunadas ao fiel teor normativo da proteção garantida às marcas e aos símbolos industriais.

Marcos José Nogueira de Souza Filho marcosjnsfilho@hotmail.com Mestre em Direito Constitucional e Especialista em Direito Público. Professor de Instituições de Direito no Curso de Administração e de Direito Administrativo no Curso de Direito do Centro Universitário Christus.. Professor de Direito Constitucional da Universidade de Fortaleza. Advogado.

Fortaleza - CE - BR.
Palavras-chave: Propriedade Industrial. Marcas. Superior Tribunal de Justiça.

\section{INTRODUÇÃO}

A atividade econômica conta com a proteção garantida pela Constituição Federal de 1988, que privilegia a livre iniciativa e a economia de mercado. Em várias passagens do texto constitucional, fica evidente o caráter capitalista que o legislador constituinte quis dispensar à organização socioeconômica brasileira, garantindo condições plenas ao exercício da atividade empresarial. Esses valores sociais da livre iniciativa, a exemplo dos valores sociais do 
trabalho, mereceram do legislador constituinte a condição de fundamentos da República Federativa do Brasil (BRASIL, 1988) (art. $1^{\circ}$, inc. IV). Destarte, a livre concorrência, juntamente com outros elementos também não menos relevantes, galgou a qualidade de um dos princípios da atividade econômica elencados no art. 170. Corroborando esta tendência, a Constituição assegura "a todos o livre exercício de qualquer atividade econômica, independentemente de autorização de órgãos públicos, salvo nos casos previstos em lei" (art. 170, parágrafo único) (BRASIL, 1988, on-line).

Visando à garantia da livre concorrência e, ao mesmo tempo, à imposição de restrições à concorrência desleal, a Carta Magna (BRASIL, 1988 , on-line) oferece às indústrias a proteção "à propriedade das marcas, aos nomes de empresas e a outros signos distintivos" (art. $5^{\circ}$, inc. XXIX). Tal proteção incide, além de marcas, nomes e signos, sobre emblemas, logotipos e insígnias, tanto das empresas como também de seus respectivos produtos.

Não obstante todo o tratamento legislativo dispensado à matéria, é mais comum do que se imagina a afronta a tais mandamentos constitucionais, especialmente a cargo de empresas ou indústrias que tendem a se aproveitar indevidamente de marcas consolidadas e já consagradas no gosto do consumidor, por meio do lançamento de produtos como nome e/ou emblemas assemelhados.

Sobre o assunto, recentemente o $\mathrm{Su}-$ perior Tribunal de Justiça, em atendimento à legislação pertinente e almejando garantir a livre concorrência, proibiu a divulgação e comercialização de produtos com embalagens e anúncios muito parecidos com o de empresas concorrentes e já conhecidas no mercado, no intuito escuso e ilegítimo de fisgar o consumidor mais inadvertido.

Este entendimento jurisprudencial, antecedido de análise doutrinária sobre o assunto, constituirá o objeto do presente ensaio, que marca um ponto em comum entre as ciências jurídicas e as ciências administrativas, levando a cargo o comportamento probo e franco que os empresários, administradores e indutriais devem possuir em face da livre iniciativa e concorrência leal.

Neste sentido, aproveitar-se-ão mais as fontes jurisprudenciais do que as doutrinárias e legislativas, a partir de um prisma crítico acerca das recentes decisões judiciais emanadas pelo Superior Tribunal de Justiça, pedindo-se socorro aos ensinamentos doutrinários e às regras normativas apenas em caráter introdutório, subsidiário e esporádico.

Afinal, o objetivo deste ensaio acadêmico revela sua importância por meio da análise do entendimento do Poder Judiciário na solução de conflitos inerentes à atividade empresarial e à livre concorrência, especificamente quanto à proteção das marcas e inventos industriais, que constituem relevantes instrumentos inerentes à imagem e à individualização de cada sociedade empresária na consecução de sua premissa maior: o exercício da atividade econômica.

\section{DA TITULARIDADE DOS DIREI- TOS FUNDAMENTAIS RELATIVOS À PROPRIEDADE INDUSTRIAL}

Muito ainda se discute em doutrina acerca da titularidade dos direitos fundamentais individuais, a exemplos dos previstos constitucionalmente no art. $5^{\circ}$. Na verdade, a celeuma está presente na perspectiva daqueles que se enquadrariam na qualidade de destinatários dos direitos individuais. À primeira vista, poder-se-ia limitar tais direitos às pessoas físicas apenas, até mesmo em razão do viés humano dos direitos fundamentais, especialmente aqueles citados no caput do art. $5^{\circ}$ (vida, liberdade, igualdade, segurança e propriedade) (BRASIL, 1988).

Não obstante, a discussão parece perder força na medida em que mais e mais constitucionalistas se posicionam pela aplicabilidade dos direitos fundamentais individuais no contexto também das pessas jurídicas, e não restrita às pessoas naturais. Assim, nada mais correto do que entender a pessoa jurídica (sociedade empresária, sociedade civil, associação etc.) 
como também destinatária de direitos como segurança, propriedade, livre acesso ao Judiciário, imagem e honra, direito de petição etc.

Este, entretanto, não parece ser o posicionamento de autores do naipe de José Afonso da Silva e Manoel Gonçalves Ferreira Filho, para quem as pessoas jurídicas não poderiam ser beneficiárias de direitos fundamentais. Veja-se o que diz, sobre o assunto, o primeiro daqueles constitucionalistas, nivelando os direitos fundamentais aos direitos humanos: $\mathrm{O}$ dispositivo que define e assegura a propriedade industrial "está entre os dos direitos individuais, sem razão plausível para isso, pois evidentemente não tem natureza de direito fundamental do homem" (SILVA, 2009, p. 278).

Já Manoel Gonçalves Ferreira Filho também critica a opção do legislador constituinte em incluir o direito de propriedade industrial dentro do rol de direitos usufruíveis pelas pessoas jurídicas:

Sem dúvida, essas formas de propriedade, esses direitos aí reconhecidos, são importantes para a estrutura econômica sobre a qual se ergue nossa Constituição. É indiscutível exagero, porém, incluí-los no rol dos direitos fundamentais. Por outro lado, a Constituição não lhes atribui garantia especial, de modo que sua enunciação no art. $5^{\circ}$ não impede que a lei ordinária fixe o seu conteúdo (FERREIRA FILHO, 2010, p. 339-340).

Entretanto, as vozes destes autores citados parecem ecoar sozinhas no universo doutrinário da teoria dos direitos fundamentais. A doutrina majoritária, consubstanciada em um entendimento mais coerente, posiciona-se a favor da extensão dos direitos individuais às pessoas jurídicas.

Regina Maria Macedo Nery Ferrair, por exemplo, destaca que o que está por trás deste entendimento é a própria condição da pessoa jurídica, como uma espécie de ficção jurídica formada a partir da conjugação da vontade de uma coletividade de pessoas físicas:
Quando se analista a literalidade do dispositivo em comento (art. $5^{\circ}$ ), pode-se convir que abarque só as pessoas físicas ou naturais, mas não é bem assim. As pessoas jurídicas, por serem entes abstratos, só se expressam por meio de pessoas físicas, o que leva a entender que a proteção do indivíduo depende, em certa medida, do amparo conferido às pessoas jurídicas, às entidades jurídicas personalizadas (FERRAIR, 2011, p. 536).

Não menos lúcida é a observação de Alexandre de Moraes sobre o tema:

Igualmente, as pessoas jurídicas são beneficiárias dos direitos e garantias individuais, pois reconhece-se às associações o direito à existência, o que de nada adiantaria se fosse possivel excluí-las de todos os seus direitos. Dessa forma, os direitos enunciados e garantidos pela Constituição são de brasileiros, pessoas físicas ou jurídicas $[. .$.$] , pois têm direito à existência,$ à segurança, à propriedade, à proteção tributária e aos remédios constitucionais (MORAES, 2010, p. 35).

Diante do exposto, parecem inválidas quaisquer críticas à inclusão da propriedade industrial no âmbito da lista de direitos fundamentais individuais constante do art. $5^{\circ}$ da Constituição Federal, na medida em que parte daqueles direitos são, sim, usufruíveis por pessoas jurídicas, sejam dotadas de finalidades lucrativas (sociedades) ou não (associações).

\section{LEGISLAÇÃO PERTINENTE À PROPRIEDADE DAS MARCAS}

A propriedade industrial, garantida constitucionalmente, abrange não somente a intelectualidade de inventos, mas também os símbolos, as marcas, os logotipos, os emblemas, enfim tudo aquilo vinculado à imagem e à atividade da empresa. Trata-se do teor do inc. XXIX do art. $5^{\circ}$ da Constituição Federal, se- 
gundo o qual “a lei assegurará $[. .$.$] proteção às$ criações industriais, à propriedade das marcas, aos nomes de empresas e a outros signos distintivos, tendo em vista o interesse social e o desenvolvimento tecnológico e econômico do País" (BRASIL, 1988, on-line).

A propriedade industrial, segundo José Afonso da Silva, constitui "propriedade de bens incorpóreos: privilégio de invenção industrial, que assegura ao inventor o direito de obter patente que lhe garanta [...] o direito exclusivo de utilização do objeto da petente e o consequente direito de impedir que terceiros o faça" (SILVA, 2009, p. 278).

A justificativa para a proteção constitucional às empresas, em razão de seus inventos industriais, é apresentada por Uadi Lammêgo Bulos, para quem

A propriedade industrial é o conjunto de direitos que recaem sobre invenções destinadas à exploração econômica. [...] A tutela da propriedade industrial possui sentido. Inúmeras vezes, as descobertas científicas e até as realizações industriais não trazem qualquer recompensa para seus autores. Quantos cientistas e inventores ficam desamparados juridicamente devido às deficiências da legislação? Daí o mínimo que pode ser feito: tutelar, juridicamente, as novidades reveladas ao mundo, outrora ignoradas, e que enriquecem o acervo espiritual do homem, trazendo-lhe benefícios (BULOS, 2012, p. 619).

Nestes termos, a empresa que primeiro cria e registra seus símbolos, nomes e emblemas tem preferência de uso de suas marcas sobre outras empresas que, a pretexto de atuarem na mesma área econômica, pegam carona no consolidado reconhecimento que a primeira mantém junto à classe consumidora. Isso é o que também ensinam Luiz Alberto David Araújo e Vidal Serrano Nunes Júnior: "As marcas de indústria e comércio têm a finalidade de relacionar o produto ao seu fabricante ou ao seu distribuidor. Nesse sentido, as empresas pos- suem nomes ou sinais que igualmente estão protegidos pelo texto constitucional" (ARAÚJO; NUNES JÚNIOR, 2012, p. 206).

A marca da empresa garante-lhe, ainda, privilégio exclusivo de utilização, devendo o Poder Público garantir esta proteção. Na prática, a atribuição de promover a inscrição de marcas e patentes, bem como de fiscalizar sua utilização, recai sobre uma entidade denominada Instituto Nacional de Propriedade Industrial (INPI). Esta, segundo seu site, "é responsável pelo aperfeiçoamento, disseminação e gestão do sistema brasileiro de concessão e garantia de direitos de propriedade intelectual para a indústria" (INPI, 2016, on-line).

E mais:

Entre os serviços do INPI, estão os registros de marcas, desenhos industriais, indicações geográficas, programas de computador e topografias de circuitos, as concessões de patentes e as averbações de contratos de franquia e das distintas modalidades de transferência de tecnologia. Na economia do conhecimento, estes direitos se transformam em diferenciais competitivos, estimulando o surgimento constante de novas identidades e soluções técnicas (INPI, 2016, on-line).

Assim, é o INPI a entidade responsável pelo controle e fiscalização sobre o direito de utilização de marcas e patentes industriais, de domínio do criador ou inventor. É ele também o compente para receber e registrar pedidos de patentes e marcas, bem como de negar o registro se enventualmente a marca se encontra em situação irregular, em razão de proposital semelhança com outra já existente.

$\mathrm{O}$ caráter público presente no controle e na fiscalização das marcas e patentes é corroborado por Gilmar Ferreira Mendes e Paulo Gustavo Gonet Branco:

Tem-se aqui, pois, garantia institucional quanto ao direito de propriedade industrial, que obriga o Poder Público 
a instituir o sistema de proteção e a preservá-lo, tendo em vista os contornos estabelecidos pela Constituição. [...] Identifica-se, também, a propriedade industrial enquanto direito subjetivo assegurado contra eventuais ofensas às posições jurídicas garantidas pela ordem constitucional (MENDES; BRANCO, 2013, p. 328).

Em nível infraconstitucional, coube à Lei $\mathrm{n}^{\circ}$ 9.279, de 14 de maio de 1996 (BRASIL, 1996), regulamentar a propriedade industrial, regulamentando o inc. XXIX do art. $5^{\circ}$ da Constituição Federal, há pouco transcrito. É também esta Lei que veda a prática ilícita de utilizar símbolos ou marcas semelhantes às de empresas já consagradas, na tentativa fraudulenta de dissimular e enganar o consumidor, no momento da escolha de um produto.

Segundo a Lei da Propriedade Industrial, não é registrável como marca a "reprodução ou imitação, no todo ou em parte, ainda que com acréscimo, de marca alheia registrada, para distinguir ou certificar produto ou serviço idêntico, semelhante ou afim, suscetível de causar confusão ou associação com marca alheia" (art. 124, inc. XIX) (BRASIL, 1996, on-line).

A prática de certas empresas, proibida por este dispositivo legal, consistente em aproveitar o reconhecimento de uma marca já consolidada de empresa concorrente e criando uma semelhante, contrange a livre iniciativa e instaura a concorrência desleal, devendo ser por isto mesmo desestimulada e abolida das relações jurídicas que permeiam a atividade econômica.

Neste sentido, verifica-se o esforço do Judiciário brasileiro na manutenção do equilíbrio econômico entre empresas concorrentes, em diversas áreas da Administração privada, evitando práticas abusivas que afrontem os princípíos da atividade econômica fixados constitucionalmente. Sobre o assunto, tem-se a destacar a seguir decisões recentes, no âmbito do Superior Tribunal de Justiça, acerca da proteção à propriedade industrial no Brasil.

\section{O POSICIONAMENTO DO SUPE- RIOR TRIBUNAL DE JUSTIÇA}

O Superior Tribunal de Justiça, na qualidade de um dos órgãos de maior instância no âmbito da estrutura judiciária brasileira, vem reiteradamente julgando casos que envolvem o tema discutido neste ensaio. As decisões se dão no sentido de garantir plena aplicabilidade à legislação de proteção industrial, enaltecendo a livre iniciativa e punindo a concorrência desleal, conforme exige a Constituição.

Entre as lides judiciais que alcançaram a instância do STJ, destacam-se dois casos bem emblemáticos, assim caracterizados por envolverem marcas de produtos bastante conhecidos pelo consumidor brasileiro. São os casos da Bombril, tradicional indústria de produtos de limpeza, e do Cheetos, que produzem salgadinhos à base de milho bem a gosto do público infantil.

Aproveita-se para reiterar a justificativa da escolha destas duas marcas não só por sua submissão a complexas lides judiciais, mas também - e principalmente - pelo amplo respaldo e conhecimento popular de que são detentores. Afinal, deve-se a tal qualidade a iniciativa de marcas menores e menos conhecidas em tentar reaproveitar a fisiononomia dos emblemas e das embalagens e ludibriar o consumidor.

\section{O CASO CHEETOS}

O Superior Tribunal de Justiça, por meio de sua Quarta Turma, reconheceu a similitude entre as marcas Cheetos, da empresa multinacional PepsiCo e líder de mercado, e Cheesekitos, da empresa Trigomil Produtos Alimentícios. Segundo o site daquele órgão jurisdicional (BRASIL, 2013a, on-line), o Ministro Luis Felipe Salomão, em seu relatório, entendeu que "o registro da marca violou o artigo 124, XIX, da Lei da Propriedade Industrial, e não atende aos objetivos da Política Nacional de Relações de Consumo, sendo de rigor a sua anulação."

O recurso foi proveniente de ação 
judicial proposta não somente contra a empresa Trigomil, mas também contra o próprio Instituto Nacional da Propriedade Industrial (INPI), entidade responsável pelo registro de marcas e patentes no Brasil, trazendo, por esse motivo, a competência jurisdicional para a Justiça Federal, ex $v i$ o disposto no art. 109, inc. I, da Constituição Federal.

Em função da similitude entre as marcas, o STJ determinou a nulidade do registro da marca Cheesekitos. A justificativa, para tanto, foi a reprodução quase fiel de elementos da marca Cheetos, registrada anteriormente. A obrigação pela análise preventiva da semelhança entre as marcas seria de responsabilidade do INPI, razão pela qual esta entidade configurou também no polo passivo da demanda judicial.

Não obstante, não é suficiente, para a anulação do registro da marca, a semelhança entre as marcas, mas se ambas mantêm em comum a mesma área da indústria ou do comércio. Este segundo requisito restou presente no caso que examina, uma vez que presentes no mesmo campo alimentício, qual são os salgadinhos industrializados e direcionados especialmente à clientela infantil.

Ainda segundo o site, para o Ministro Luis Felipe Salomão, a possibilidade de confusão ou associação entre as marcas ficou nítida no caso, principalmente porque o público alvo do produto de ambas as empresas são as crianças, "que têm inegável maior vulnerabilidade, por isso são denominadas pela doutrina como consumidores hipervulneráveis" (BRASIL, 2013, on-line).

Sobre o assunto, não se descobriu o modelo de embalagem utilizado pela empresa produtora do Cheesekitos, até porque já havia sido proibida a sua divulgação. Entretanto, coletam-se exemplos de salgadinhos que apelam à similitude de uma marca já consagrada, a exemplo do que se vê a seguir:

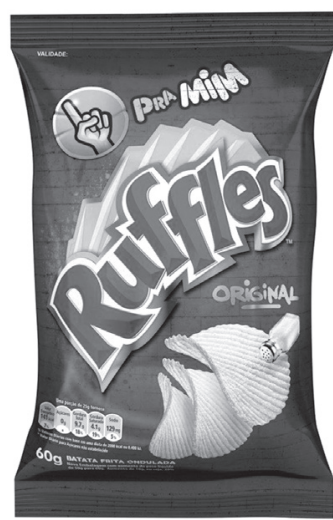

Figura 1 - Embalagem de Ruffles, da PepsiCo Fonte: (SARAGUATO, 2011, on-line).

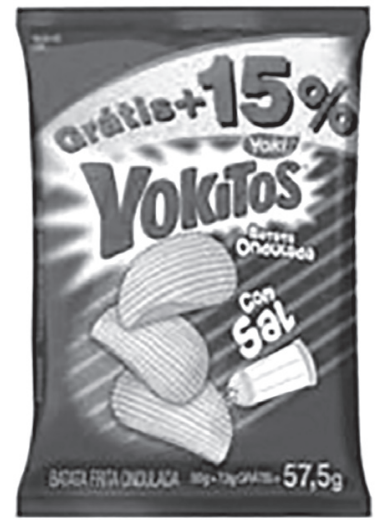

Figura 2 - Embalagem de Yokitos, da Yoki Fonte: (O QUE VEJO POR AÍ, 2010, on-line).

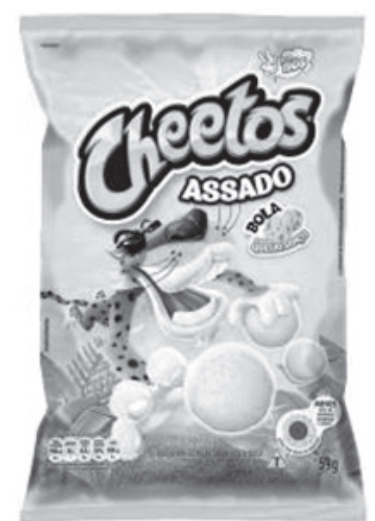

Figura 3 - Embalagem de Cheetos, da PepsiCo Fonte: (DIÁRIO DO NORDESTE, 2015, on-line). 


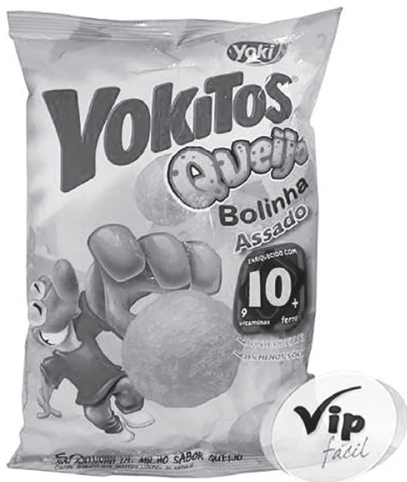

Figura 4 - Embalagem de Yokitos, da Yoki Fonte: (VIP FÁCIL, 2016, on-line).

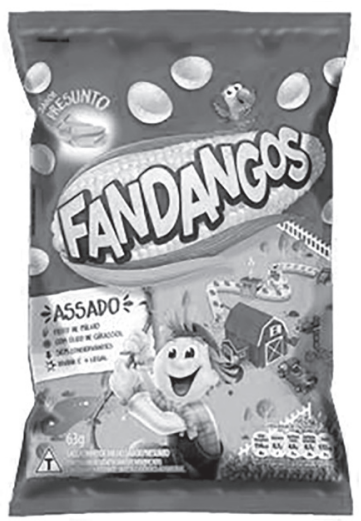

Figura 5 - Embalagem de Fandangos, da PepsiCo Fonte: (PEPSICO, 2016, on-line).

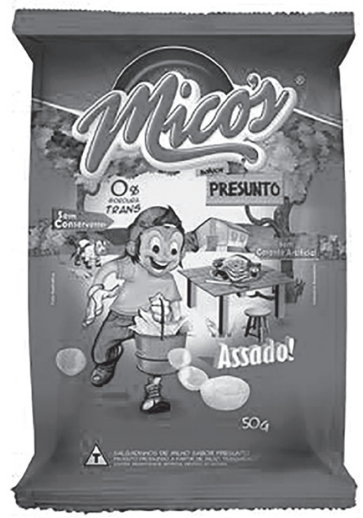

Figura 6 - Embalagem de Mico's, do Grupo Cicopal Fonte: (GRUPO CICOPAL, 2016, on-line)

\section{O CASO BOMBRIL}

Outro caso bastante emblemático sobre o assunto também envolve marca bastante co- nhecida do consumidor brasileiro. Trata-se da marca Bombril, especializada em produtos de limpeza. No caso, outra empresa, também fabricante de produtos de limpeza, teria tirado proveito do reconhecimento da marca Bombril, já tradicional e consolidada no mercado, lançando produtos com nome e marca similar, bem como gerando confusão para o consumidor no momento da compra. A foto abaixo dá uma ideia da similitude entre as marcas:

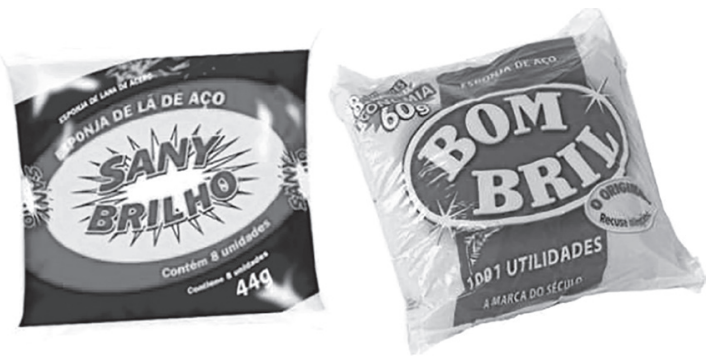

Figura 7 - Embalagens de Sany Brilho, da Sany do Brasil, e de Bombril, da empresa homônima Fonte: (DIÁRIO DE ILHÉUS, 2013, on-line).

A Quarta Turma do STJ foi a responsável pelo julgamento da lide, envolvendo as empresas Bombril Mercosul S/A e Sany do Brasil Indústria e Comércio de Produtos de Limpeza. A relatoria do processo coube ao Ministro Sidnei Beneti, cujo entendimento ratificou a decisão anterior, emanada pelo Tribunal de Justiça do Estado de São Paulo, que também se posicionou pela similitude irregular das marcas.

Segundo o site do Superior Tribunal de Justiça (BRASIL, 2013b, on-line), o acórdão se baseou na "homofonia entre os nomes dos seus produtos [...] e a identidade das embalagens similares". Constam da reportagem, ainda, os seguintes dizeres:

A tradicional marca, que remonta à década de 1940, ajuizou ação contra a Sany do Brasil Indústria e Comércio de Produtos de Limpeza. Em primeiro grau, o juiz determinou que a ré se abstivesse de produzir, importar e comercializar os produtos assinalados pelas marcas "Bril" e "Brilho", bem como reproduzir em suas embalagens marca ou forma de apresentação que 
se confundam com produtos da Bombril (BRASIL, 2013b, on-line).

O que se diagnostica, a partir da comparação entre as duas marcas, é a semelhança entre elas, o que de fato gera confusão no momento da escolha do produto. E mais: ambos os produtos têm a mesma finalidade e estão disponibilizados próximos nas prateleiras dos supermercados. A foto a seguir também expõe a semelhança das embalagens e dos nomes: preferência não a marca mais conhecida, mas a que primeiro cumpriu suas obrigações de registro.

\section{CONCLUSÃO}

Existem marcas no mercado que, de tão reconhecidas e consagradas, são, muitas vezes, confudidas como marcas únicas e exclusivas, como se não houvesse outras empresas que também oferecessem o mesmo serviço ou pro-

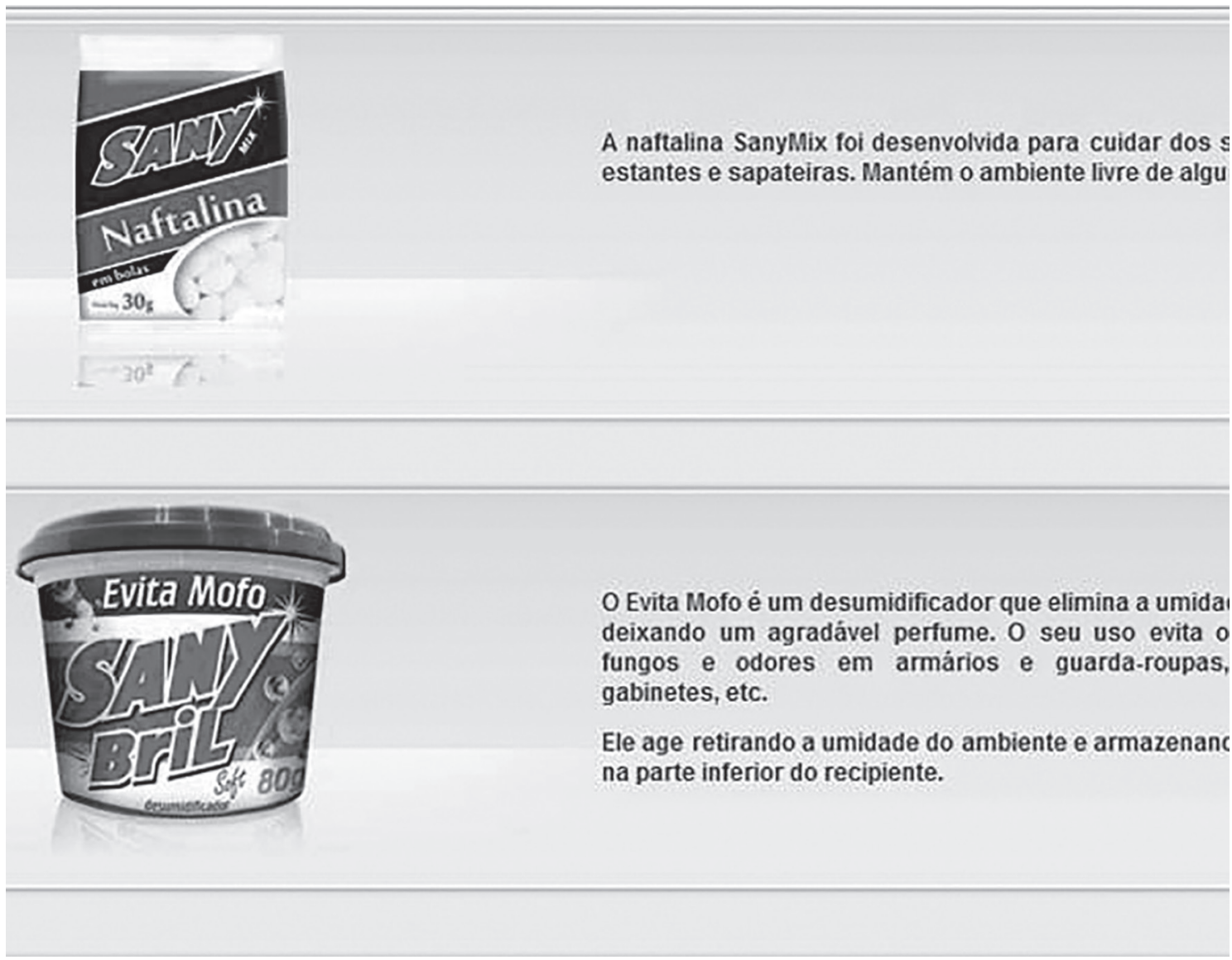

Figura 8- Divulgação dos produtos da Sony do Brasil Fonte: (GLOBO.COM, 2013, on-line)

O último órgão jurisdicional em que tramitou o processo, antes do STJ, foi o Tribunal de Justiça do Estado de São Paulo, para quem houve "induvidoso aproveitamento parasitário". Ainda segundo o site do STJ, a decisão reconheceu a concorrência desleal pela possibilidade de confusão entre as marcas, merecendo duto. É o que se pode dizer de empresas como a Bombril e de produtos como o Cheetos.

Aliás, é bastante usual imaginar um produto por intermédio da marca mais conhecida, criando o que a literatura denomina de metonímia, em que se emprega um termo em lugar de outro, como a marca pelo produto. É assim no 
caso da Gilete, da Coca-Cola, dos Correios e, especificamente, da Bombril.

Este cenário é consequência da imagem que a empresa, ao longo de anos, consolida no mercado. À custa de muita tradição, a marca da empresa passa a ser de conhecimento coletivo, devendo o Estado protegê-la contra investidas ilícitas e tendenciosas de empresas concorrentes, que visam à utilização de emblema ou símbolos muito próximos dos tradicionais, repercutindo negativamente na livre concorrência e gerando confusão no momento em que o consumidor escolhe o produto de sua conveniência.

$\mathrm{Na}$ condição de direito fundamental de caráter individual, usufruídos por empresas e indústrias, a exclusividade do uso de marcas e símbolos patenteados está garantida juridicamente, seja por meio de legislação específica, seja por decisões judiciais correlatas e embasadas nos ditames da justiça e do bom senso.

Trata-se do que se verificou, efetivamente, por meio da análise crítica do posicionamento do Superior Tribunal de Justiça sobre o cenário, rechaçando condutas irregulares de empresas e indústrias que, ainda que fabricantes de produtos de qualidade, se aproveitam do respaldo popular que outras marcas já conseguiram consolidar.

Assim, este ensaio propiciou a análise do tratamento que a doutrina, a legislação e, principalmente, a jurisprudência dão à matéria, evidenciando o comprometimento com os princípios gerais da atividade econômica, especialmente a livre iniciativa e o desetímulo à concorrência desleal.

\section{PROTECTING INDUSTRIAL PROPERTY OF TRADEMARKS IN THE VISION OF THE SUPERIOR COURT OF JUSTICE}

\begin{abstract}
The practice, reprehensible from a legal point of view, but very common, to create brands and symbols of similar goods or products to those already established and consolidated in the
\end{abstract}

market, confuses consumers at the moment that they decide to purchase a product. This scenario has been submitted to the judiciary, specifically to the Superior Court of Justice on several occasions, but two cases drew attention because of the reputation of the brands: Bombril, whose symbol is recognized all over the area of cleaning and home care, and Cheetos snacks, favorites of taste of the younger ones. Thus, businesses and industries, even producing quality products, prefer to wile, using symbols or emblems very close to the brands that are already consecrated, in the irregular attempt to attract consumers and violating the basic principles of free enterprise and fair competition. Given the situation, the Judiciary has consolidated jurisprudence in order to effectively protect brands, symbols and emblems already enshrined in public taste. The most recent court decisions on the matter are precisely the basic theme of this essay, which will be built from relevant judicial reviews and, alternatively, of doctrinal studies and normative rules inherent to the subject. By the way, such decisions don't seem to deserve any repairs as they coadunate the faithful normative content of the guaranteed protection of trademarks and industrial symbols.

Keywords: Industrial Property. Brands. Superior Court of Justice.

\section{LA PROTECCIÓN A LA PROPIEDAD INDUSTRIAL DE LAS MARCAS EN LA VISIÓN DEL SUPERIOR TRIBUNAL DE JUSTICIA}

\section{RESUMEN}

Más común de lo que se imagina es la práctica, reprobable del punto de vista jurídico, de criarse marcas y símbolos de bienes o productos similares a aquellos ya consagrados y consolidados en el mercado, haciendo con que el consumidor se confunda al elegir el producto. Este escenario fue sometido al Poder Judiciario, específicamente al Superior Tribunal de Justicia, en variadas ocasiones, pero dos casos llamaron 
la atención por la notoriedad de las marcas: la Bombril, cuyo símbolo es de veras reconocido en el área de limpieza e higiene doméstica, y los ganchitos Cheetos, bien a gusto de la clientela infantil. Así, empresas e industrias, aunque generen productos de calidad, prefieren la artimaña de utilizar en sus envases símbolos o emblemas muy próximos de aquellos de marcas ya reconocidas, en la tentativa irregular de atraer consumidores e hiriendo los principios de la libre iniciativa y de la concurrencia leal. Ante esa coyuntura, el Poder Judiciario viene consolidando jurisprudencia con el objetivo de efectivamente proteger marcas, símbolos y emblemas ya consagrados en el gusto del público. Las más recientes decisiones judiciales acerca del asunto constituyen precisamente el tema básico del presente ensayo, que será construido a partir del análisis jurisprudencial pertinente, así como, subsidiariamente, de los estudios doctrinarios y de las reglas normativas inherentes al asunto. Además, dichas decisiones aparentan no necesitar cualquier concierto, ya que son conciliadas al fiel tenor normativo de la protección garantizada a las marcas y a los símbolos industriales.

Palabras clave: Propiedad Industrial. Marcas. Superior Tribunal de Justicia.

\section{REFERÊNCIAS}

ARAÚJO, Luiz Alberto David; NUNES JÚNIOR, Vidal Serrano. Curso de direito constitucional. 16. ed. São Paulo: Verbatim, 2012.

BRASIL. Constituição (1988). Constituição da República Federativa do Brasil. Palácio do Planalto, Brasília, DF, 1988. Disponível em: $<$ http://www.planalto.gov.br/ccivil_03/Constituicao/ConstituicaoCompilado.htm>. Acesso em: 27 jul. 2016.

BRASIL. Lei no 9.279, de 14 de maio de 1996. Regula direitos e obrigações relativos à propriedade industrial. Palácio do Planalto, Brasília, DF, 1996. Disponível em: <http://www.
planalto.gov.br/ccivil_03/leis/L9279.htm>. Acesso em: 27 jul. 2016.

BRASIL. Superior Tribunal de Justiça. Pesquisa Cheetos. Disponível em: <http://www.stj. jus.br/portal_stj/publicacao/engine.wsp?tmp. area $=398 \&$ tmp.texto $=108943 \&$ tmp.area_anterior $=44 \&$ tmp.argumento_pesquisa $=$ cheetos $>$. Acesso em 19 mar. 2013a.

BRASIL. Superior Tribunal de Justiça. Pesquisa Bombril. Disponível em: <http://www.stj. jus.br/portal_stj/publicacao/engine.wsp?tmp. area $=398 \&$ tmp.texto $=108502 \&$ tmp.area anterior $=44 \&$ tmp.argumento pesquisa $=$ bombril $>$. Acesso em 8 fev. 2013b.

BULOS, Uadi Lammêgo. Curso de direito constitucional. 7. ed. São Paulo: Saraiva, 2012.

DIÁRIO DO NORDESTE. Cheetos está de cara nova. 2015. Disponível em: $<$ http://blogs.diariodonordeste.com.br/target/produtos/cheetos-esta-de-cara-nova/>. Acesso em: 27 jul. 2016.

DIÁRIO DE ILHÉUS. Bombril obtém vitória em processo contra cópia de embalagem pela sany. 2013. Disponível em: <http:// www.diariodeilheus.com.br/v1/2013/02/12/ bombril-obtem-vitoria-em-processo-contra-copia-de-embalagem-pela-sany/>. Acesso em: 7 maio 13.

FERRAIR, Regina Maria Macedo Nery. Direito constitucional. São Paulo: Revista dos Tribunais, 2011.

FERREIRA FILHO, Manoel Gonçalves. Curso de direito constitucional. 36. ed. São Paulo: Saraiva, 2010.

GLOBO.COM. Bombril obtém vitória em processo contra cópia de embalagem pela Sany. 2013. Disponível em: <http://g1.globo. com/economia/noticia/2013/02/bombril-obtem-vitoria-em-processo-contra-copia-de-embalagens.html>. Acesso em: 7 maio 2013. 
GRUPO CICOPAL. Salgadinho de milho micos presunto. Disponível em: <http://www. grupocicopal.com.br/produtos/salgadinho-micos-presunto/>. Acesso em: 27 jul. 2016.

INSTITUTO NACIONAL DA PROPRIEDADE INDUSTRIAL - INPI. Estrutura. Disponível em: $<$ http://www.inpi.gov.br/sobre/estrutura $>$. Acesso em: 27 jul. 2016.

MENDES, Gilmar Ferreira; BRANCO, Paulo Gustavo Gonet. Curso de direito constitucional. 8. ed. São Paulo: Saraiva, 2013.

MORAES, Alexandre de. Direito constitucional. 26. ed. São Paulo: Atlas, 2010.

O QUE VEJO POR AÍ. Yoki lança embalagem maior para yokitos. 2010. Disponível em: <https://oquevejoporai.wordpress. com/2010/02/24/yoki-lanca-embalagem-maior-para-yokitos/>. Acesso em: 27 jul. 2016.

PEPSICO. Fandangos. Disponível em: $<$ http:// www.pepsico.com.br/fandangos $>$. Acesso em: 27 jul. 2016.

SARAGUATO. Saraguato promoverá Ruffles em 2012. 2011. Disponível em: <https:// saraguato.wordpress.com/2011/11/16/saraguato-promovera-ruffles $\%$ C2\%AE-em-2012/>. Acesso em: 27 jul. 2016.

SILVA, José Afonso da. Curso de direito constitucional positivo. 32. ed. São Paulo: Malheiros Editores, 2009.

VIP FÁCIL. Salgadinho yokitos bolinha sabor queijo 45g. Disponível em: <https://www.vipfacil.com.br/produto/18632-salgadinho-yokitos-bolinha-sabor-queijo-45g>. Acesso em: 27 jul. 2016. 